\title{
Resposta à Carta de Drumond
}

\author{
Reply to Letter by Drumond
}

Respuesta a la Carta de Drumond

\author{
Sandra Costa Fonseca 1 \\ Pauline Lorena Kale 2 \\ Graça Helena Maia do Canto Teixeira 3 \\ Vania Gloria Silami Lopes 3
}

doi: 10.1590/0102-311X00206821

Recebemos com muita alegria a Carta às Editoras de autoria de Eliane Drumond 1, pesquisadora reconhecida da área de saúde pública.

Percebemos que alcançamos nosso objetivo de estimular a reflexão e a discussão sobre os óbitos fetais, ainda tão frequentes no país.

Partilhamos preocupação acerca da idade gestacional, ressaltando que a invisibilidade dos óbitos fetais se reflete também na qualidade dos dados. Utilizamos o peso ao nascer de $500 \mathrm{~g}$ como critério de inclusão, além da idade gestacional de 22 semanas, mas, inadvertidamente, não comentamos sobre na seção Métodos 2.

Por último, concordamos com a importância de, além de usar uma classificação padronizada, trabalhar a evitabilidade por faixas de peso. Como relatado no artigo, mais da metade dos óbitos ultrapassou o peso ao nascer de $1.500 \mathrm{~g}$, configurando claramente o potencial de evitabilidade 2 .

No atual cenário, em que a ciência sofre tantos ataques, é reconfortante o retorno de nossos pares da academia!
1 Instituto de Saúde Coletiva, Universidade Federal

Fluminense, Niterói, Brasil.

2 Instituto de Estudos de

Saúde Coletiva, Universidade

Federal do Rio de Janeiro, Rio de Janeiro, Brasil.

3 Departamento de Patologia, Universidade Federal

Fluminense, Niterói, Brasil.

Correspondência

S. C. Fonseca Instituto de Saúde Coletiva, Universidade Federal Fluminense.

Rua Marquês de Paraná 303, 3o andar, Anexo HUAP, Niterói, RJ 24033-900, Brasil.

sandracfonseca@yahoo. com.br 


\section{Colaboradores}

Todas as autoras particparam igualmente na produção do texto.

\section{Informações adicionais}

ORCID: Sandra Costa Fonseca (0000-0001-5493494X); Pauline Lorena Kale (0000-0001-54399158); Graça Helena Maia do Canto Teixeira (00000001-6483-8695); Vania Gloria Silami Lopes (00000002-6656-5763).
1. Drumond EF. Precisamos falar sobre evitabilidade dos óbitos fetais no Brasil. Cad Saúde Pública 2021; 37:e00196121.

2. Fonseca SC, Kale PL, Teixeira GHMC, Lopes VGS. Evitabilidade de óbitos fetais: reflexões sobre a Lista Brasileira de Causas de Mortes Evitáveis por intervenção do Sistema Único de Saúde. Cad Saúde Pública 2021; 37:e00265920. 